\title{
Factors Affecting Latent Infection of Prune Fruit by Monilinia fructicola
}

\author{
Yong Luo and Themis J. Michailides
}

Department of Plant Pathology, University of California, Davis, Kearney Agricultural Center, Parlier 93648. Accepted for publication 15 May 2001.

\begin{abstract}
Luo, Y., and Michailides, T. J. 2001. Factors affecting latent infection of prune fruit by Monilinia fructicola. Phytopathology 91:864-872.

Experiments were conducted in three prune orchards in California. In each orchard, inoculations with Monilinia fructicola, the causal agent of brown rot of stone fruits, were performed on branches of trees at bloom and fruit developmental stages. Five inoculum concentrations were used in each inoculation. Six and four wetness durations were created for each inoculum concentration at bloom and fruit developmental stages, respectively. Fruit were harvested 3 weeks before commercial harvest. The overnight freezing incubation technique was used to promote sporulation and to determine incidence of latent infection (ILI) of fruit brown rot. No differences in ILI among locations were found. A seasonal pattern of

increased to reach the highest level at pit hardening stage. Subsequently, fruit susceptibility to latent infection decreased, reaching the lowest level in early June at embryo growth stage. Thereafter, the susceptibility increased again with fruit development and maturity until harvest. Linear relationships between ILI and inoculum concentration were obtained for most combinations of growth stage and wetness duration. Incidence of latent infection increased linearly with increased wetness duration at bloom stage and increased exponentially with increased wetness duration at early and late fruit developmental stages. The optimum temperatures for latent infection at pit hardening stage ranged from 14 to $18^{\circ} \mathrm{C}$, but the effect of temperature on latent infection was reduced at resistant stages. The temperature range favorable to latent infection varied for different wetness durations.
\end{abstract} bloom and fruit susceptibility to latent infection was determined. Susceptibility to latent infection at bloom stage was at a moderate level and
Additional keywords: Prunus domestica, quiescent infection.
Monilinia fructicola (G. Wint.) Honey causes brown rot of stone fruits (Prunus spp.) $(1,4,17,29)$. Blossom blight caused by ascospores or conidia produced from mummies infected by $M$. fructicola may occur in the early spring $(4,16,17,28)$. Infection of fruit caused by conidia produced on infected blossoms, mummies, or thinned fruit occur secondarily and can cause economically serious yield losses $(7,12,15,30)$. Secondary infections may occur during the growing season depending on weather conditions. Previous studies $(1,17,22)$ determined the importance of nonabscised aborted fruit in trees and thinned fruit on the orchard floor infected by $M$. fructicola as sources of secondary inoculum for fruit brown rot. The significance of thinned fruit as a source of secondary inoculum in California nectarine orchards was also confirmed (11). Infected thinned fruit on the orchard floor served as sources of conidia that caused secondary infection, and sporulation of $M$. fructicola significantly correlated with the severity of preharvest and postharvest brown rot $(10,11)$. However, disease symptoms and sporulation usually do not appear on immature fruit unless favorable weather (higher humidity and optimum temperature) and cultural conditions occur. Fruit with early latent infections may become mummified and serve as sources of primary inoculum in the following spring.

In California, it is recommended that for best chemical control of blossom blight, sprays should be applied at the green tip stage when young buds start to grow and green buds appear. However, control of latent infection is still under investigation. Michailides et al. (23) found that sprays in early summer were effective in reducing brown rot at harvest and suggested possible effects on latent infection that occurred early in the season. Michailides et al.

Corresponding authors: Y. Luo and T. Michailides

E-mail addresses: yluo@uckac.edu and themis@uckac.edu

Publication no. P-2001-0702-03R

(C) 2001 The American Phytopathological Society
(20-22) determined positive correlations between incidence of latent infections (ILI) in immature prune, nectarine, and plum and fruit rot incidence at harvest and postharvest. Similarly, correlation between latent infection in immature plum fruit and fruit rot incidence at harvest was reported in Ontario, Canada (25). Recently, positive correlations of incidence of fruit rot at harvest with incidence of blossom blight and latent infection at the pit hardening stage in peach orchards in Georgia were determined (8). These findings imply that in addition to control blossom blight, infections at fruit developmental stages also need to be reduced.

Understanding the seasonal pattern of fruit susceptibility to latent infection is important to develop a control strategy for brown rot. Additionally, information about disease development affected by environments at different stages is helpful. However, few reports on seasonal patterns of fruit susceptibility to latent infection exist. Biggs and Northover (2) studied the seasonal susceptibility of detached peach fruit to infection by $M$. fructicola, and found that fruit were susceptible early in the season and became resistant at pit hardening stage. Fruit became increasingly susceptible to infection approximately 2 weeks before full ripeness. Similar trends were found in peach and nectarine orchards in a separate study (14).

Effects of temperature and wetness duration on infection of fresh or harvested stone fruit were determined in other studies $(3,6,26)$. Biggs and Northover (3) found that the optimum temperatures and wetness durations were 20 to $22.5^{\circ} \mathrm{C}$ and $18 \mathrm{~h}$, respectively, for infection of cherry fruit, and 22.5 to $25^{\circ} \mathrm{C}$ and $12 \mathrm{~h}$ for infection of peach fruit. Inoculum concentration also significantly affected brown rot development on detached cherry (24), nectarine, and peach fruit (13). However, no information on the effects of these factors on fruit brown rot of trees in fields at different fruit developmental stages is available.

Although blossom blight occurs sporadically in California, fruit brown rot is frequent, depending on inoculum in orchards and weather conditions during the growing season. Therefore, it is often necessary to develop specific orchard-based control strategies. 
Due to changes in fruit susceptibility over the season, the risk of fruit brown rot may be different at different developmental stages, even though the inoculum is consistently high and the environmental conditions are favorable in an orchard. Chemical control of brown rot after taking into account disease prediction and risk analysis could be effective to reduce fungicide resistance in the pathogen population. Quantitative relationships between latent infection and environments at different fruit developmental stages are, therefore, necessary for developing a disease prediction and risk assessment system. The objectives of this study were to (i) determine the seasonal pattern of prune fruit susceptibility to latent infection by $M$. fructicola, and (ii) determine the quantitative relationships between ILI and inoculum concentration, wetness duration, and temperature at different fruit developmental stages.

\section{MATERIALS AND METHODS}

Preparation of inoculum. An isolate of M. fructicola collected from a prune orchard and stored at the Kearney Agricultural Center, University of California in Parlier, was used in this study. This isolate was cultured in petri dishes $(10 \times 150 \mathrm{~mm})$ containing potato dextrose agar amended with $25 \%$ lactic acid $(2.6 \mathrm{ml} / \mathrm{liter})$. The dishes were incubated at $23 \pm 2{ }^{\circ} \mathrm{C}$ for 5 days in the dark. The pathogen was subcultured on new dishes under the same conditions for 5 days. Spores of $M$. fructicola were harvested by pouring $3 \mathrm{ml}$ of sterile distilled water in each petri dish and adjusted to different concentrations by averaging four hemacytometer counts.

Experimental design. The experimental design is summarized in Table 1. Three prune orchards were selected each in Yolo,
Butte, and Tehama counties in California. At each location, inoculations were conducted at five stages, one at bloom and four at fruit developmental stages. Bloom inoculations were conducted from 24 to 28 March at full bloom stage (27), once in each of the three orchards. In each inoculation, five inoculum concentrations, 1,000, 5,000, 10,000, 20,000, and 30,000 conidia per $\mathrm{ml}$ of $M$. fructicola, were used. Branches bearing 40 to 60 flowers were selected. Each branch was covered with a $1.5-\mathrm{ml}$ plastic bag $(30.4 \times$ $20.3 \times 76.2 \mathrm{~cm}$ ) and sprayed uniformly inside the bag with $50 \mathrm{ml}$ of conidia suspension for each inoculum concentration by a handheld sprayer (ACE Hardware Corporation, Oak Brook, IL). Immediately after inoculation, the branch was closed tightly in the plastic bag to create high humidity. For each experiment, inoculations were completed at approximately $1800 \mathrm{~h}$. Six wetness durations, 4, 8, 12, 16, 20, and $24 \mathrm{~h}$, were accomplished by uncovering the plastic bags at approximately 2200, 0200, 0600, 1000,1400 , and $1800 \mathrm{~h}$, respectively. Inoculated branches were checked one-half hour after uncovering bags for delay of dew period. Data of inoculations that encountered natural dew falls or rains were omitted in analysis. In most cases, inoculated branches were dry one-half hour after uncovering bags. To prevent high temperature in the inoculated bags caused by sunlight, the plastic bags for treatments of 16,20 , and $24 \mathrm{~h}$ of wetness duration were covered with paper bags $(30.4 \times 17.3 \times 36.2 \mathrm{~cm})$ from $0800 \mathrm{~h}$ until completion of the wetness duration. Five inoculum concentrations were separated on five trees, and each tree was used for the six wetness durations. Five branches of a noninoculated tree were sprayed with $50 \mathrm{ml}$ of water and were maintained wet for a duration of $16 \mathrm{~h}$ to serve as noninoculation control for each inocu-

TABLE 1. Summary of experiments at three locations in California prune orchards ${ }^{\mathrm{a}}$

\begin{tabular}{|c|c|c|c|c|c|c|c|c|c|c|c|c|c|c|c|}
\hline \multirow{2}{*}{$\begin{array}{l}\text { Location and } \\
\text { inoculation date }\end{array}$} & \multirow[b]{2}{*}{ Bloom or fruit stage } & \multirow{2}{*}{$\begin{array}{l}\text { Replicate } \\
\text { stages }\end{array}$} & \multicolumn{6}{|c|}{ Wetness duration $(\mathrm{h})^{\mathrm{b}}$} & \multicolumn{5}{|c|}{ Inoculum concentration (conidia/ml) } & \multirow{2}{*}{$\begin{array}{l}\text { Fruit size }(\mathrm{mm}) \\
\text { length/width }^{\mathrm{c}}\end{array}$} & \multirow{2}{*}{$\begin{array}{c}\text { Fruit } \\
\text { weight }(g)^{c}\end{array}$} \\
\hline & & & 4 & 8 & 12 & 16 & 20 & 24 & 1,000 & 5,000 & 10,000 & 20,000 & 30,000 & & \\
\hline \multicolumn{16}{|l|}{ Yolo (Davis) } \\
\hline 24 March & Full bloom & 1 & $\mathrm{~V}^{\mathrm{d}}$ & $\mathrm{V}$ & $\mathrm{V}$ & $\mathrm{V}$ & $\mathrm{v}$ & $\mathrm{v}$ & $\mathrm{v}$ & $\mathrm{V}$ & $\mathrm{V}$ & $\mathrm{V}$ & $\mathrm{V}$ & $\ldots$ & $\ldots$ \\
\hline 3 May & Pit hardening & 1 & $\mathrm{v}$ & $\mathrm{v}$ & $\mathrm{v}$ & $\mathrm{v}$ & $\ldots$ & $\ldots$ & $\mathrm{v}$ & $\mathrm{v}$ & $\mathrm{v}$ & $\mathrm{v}$ & $\mathrm{v}$ & $25.7 / 14.6$ & 3.4 \\
\hline 8 May & Pit hardening & 2 & $\mathrm{v}$ & $\mathrm{v}$ & $\mathrm{v}$ & $\mathrm{v}$ & $\ldots$ & $\ldots$ & $\mathrm{v}$ & $\mathrm{v}$ & $\mathrm{v}$ & $\mathrm{v}$ & $\mathrm{v}$ & $\ldots$ & $\ldots$ \\
\hline 30 May & Embryo growth & 1 & $\mathrm{v}$ & $\mathrm{v}$ & $\mathrm{v}$ & $\mathrm{v}$ & $\ldots$ & $\ldots$ & $\mathrm{v}$ & $\mathrm{v}$ & $\mathrm{v}$ & $\mathrm{v}$ & $\mathrm{v}$ & $32.5 / 25.5$ & 5.2 \\
\hline 3 June & Embryo growth & 2 & $\mathrm{v}$ & $\mathrm{v}$ & $\mathrm{v}$ & $\mathrm{V}$ & $\ldots$ & $\ldots$ & $\mathrm{v}$ & $\mathrm{v}$ & $\mathrm{V}$ & $\mathrm{v}$ & $\mathrm{v}$ & $\ldots$ & $\ldots$ \\
\hline 23 June & Late embryo growth & 1 & $\mathrm{v}$ & $\mathrm{v}$ & $\mathrm{v}$ & $\mathrm{V}$ & $\ldots$ & $\ldots$ & $\mathrm{v}$ & $\mathrm{v}$ & $\mathrm{V}$ & $\mathrm{v}$ & $\mathrm{v}$ & $35.2 / 29.7$ & 11.2 \\
\hline 23 July & Before first harvest & 1 & $\mathrm{v}$ & $\mathrm{v}$ & $\mathrm{v}$ & $\mathrm{v}$ & $\ldots$ & $\ldots$ & $\mathrm{v}$ & $\mathrm{v}$ & $\mathrm{v}$ & $\mathrm{v}$ & $\mathrm{v}$ & $37.5 / 31.1$ & 13.1 \\
\hline 24 July & Before first harvest & 2 & $\mathrm{~V}$ & $\mathrm{~V}$ & $\mathrm{v}$ & $\mathrm{v}$ & $\ldots$ & $\ldots$ & $\mathrm{V}$ & $\mathrm{v}$ & $\mathrm{v}$ & $\mathrm{V}$ & $\mathrm{v}$ & $\ldots$ & $\ldots$ \\
\hline \multicolumn{16}{|l|}{ Butte (Gridley) } \\
\hline $26 \mathrm{March}$ & Full bloom & 1 & $\mathrm{~V}$ & $\mathrm{~V}$ & $\mathrm{~V}$ & $\mathrm{~V}$ & $\mathrm{~V}$ & $\mathrm{~V}$ & $\mathrm{v}$ & $\mathrm{V}$ & $\mathrm{V}$ & $\mathrm{V}$ & $\mathrm{V}$ & $\ldots$ & $\ldots$ \\
\hline 4 May & Pit hardening & 1 & $\mathrm{~V}$ & $\mathrm{v}$ & $\mathrm{v}$ & $\mathrm{v}$ & $\ldots$ & $\ldots$ & $\mathrm{v}$ & $\mathrm{v}$ & $\mathrm{v}$ & $\mathrm{v}$ & $\mathrm{v}$ & $26.1 / 17.2$ & 3.67 \\
\hline 7 May & Pit hardening & 2 & $\ldots$ & $\ldots$ & $\ldots$ & $\mathrm{v}$ & $\ldots$ & $\ldots$ & $\mathrm{v}$ & $\mathrm{v}$ & $\mathrm{v}$ & $\mathrm{v}$ & $\mathrm{v}$ & $\ldots$ & $\ldots$ \\
\hline 31 May & Embryo growth & 1 & $\mathrm{v}$ & $\mathrm{v}$ & $\mathrm{V}$ & $\mathrm{v}$ & $\ldots$ & $\ldots$ & $\mathrm{v}$ & $\mathrm{v}$ & $\mathrm{V}$ & $\mathrm{v}$ & $\mathrm{v}$ & $32.3 / 21.7$ & 8.06 \\
\hline 4 June & Embryo growth & 2 & $\mathrm{v}$ & $\mathrm{V}$ & $\mathrm{v}$ & $\mathrm{v}$ & $\ldots$ & $\ldots$ & $\mathrm{V}$ & $\mathrm{v}$ & $\mathrm{v}$ & $\mathrm{v}$ & $\mathrm{v}$ & $\ldots$ & $\ldots$ \\
\hline 27 June & Late embryo growth & 1 & $\mathrm{v}$ & $\mathrm{v}$ & $\mathrm{v}$ & $\mathrm{v}$ & $\ldots$ & $\ldots$ & $\mathrm{v}$ & $\mathrm{v}$ & $\mathrm{V}$ & $\mathrm{v}$ & $\mathrm{v}$ & $33.5 / 24.7$ & 11.9 \\
\hline 28 June & Late embryo growth & 2 & $\mathrm{v}$ & $\mathrm{v}$ & $\mathrm{v}$ & $\ldots$ & $\ldots$ & $\ldots$ & $\mathrm{v}$ & $\mathrm{v}$ & $\mathrm{V}$ & $\mathrm{v}$ & $\mathrm{V}$ & $\ldots$ & $\ldots$ \\
\hline 21 July & Before first harvest & 1 & $\mathrm{v}$ & $\mathrm{v}$ & $\mathrm{v}$ & $\mathrm{v}$ & $\ldots$ & $\ldots$ & $\mathrm{v}$ & $\mathrm{v}$ & $\mathrm{v}$ & $\mathrm{v}$ & $\mathrm{v}$ & $34.4 / 25.1$ & 12.5 \\
\hline 22 July & Before first harvest & 2 & $\mathrm{v}$ & $\mathrm{v}$ & $\mathrm{v}$ & $\mathrm{v}$ & $\ldots$ & $\ldots$ & $\mathrm{v}$ & $\mathrm{v}$ & $\mathrm{v}$ & $\mathrm{v}$ & $\mathrm{v}$ & $\ldots$ & $\ldots$ \\
\hline \multicolumn{16}{|l|}{$\begin{array}{l}\text { Tehama } \\
\text { (Los Molinos) }\end{array}$} \\
\hline $28 \mathrm{March}$ & Full bloom & 1 & $\mathrm{~V}$ & $\mathrm{~V}$ & $\mathrm{~V}$ & $\mathrm{~V}$ & $\mathrm{v}$ & $\mathrm{v}$ & $\mathrm{V}$ & $\mathrm{V}$ & $\mathrm{V}$ & $\mathrm{V}$ & $\mathrm{V}$ & $\ldots$ & $\ldots$ \\
\hline 5 May & Pit hardening & 1 & $\mathrm{v}$ & $\mathrm{v}$ & $\mathrm{v}$ & $\mathrm{v}$ & $\ldots$ & $\ldots$ & $\mathrm{v}$ & $\mathrm{v}$ & $\mathrm{V}$ & $\mathrm{v}$ & $\mathrm{v}$ & $25.2 / 17.1$ & 3.6 \\
\hline 6 May & Pit hardening & 2 & $\mathrm{v}$ & $\mathrm{v}$ & $\mathrm{v}$ & $\mathrm{v}$ & $\ldots$ & $\ldots$ & $\mathrm{v}$ & $\mathrm{v}$ & $\mathrm{V}$ & $\mathrm{v}$ & $\mathrm{v}$ & $\ldots$ & $\ldots$ \\
\hline 1 June & Embryo growth & 1 & $\mathrm{v}$ & $\mathrm{v}$ & $\mathrm{v}$ & $\mathrm{v}$ & $\ldots$ & $\ldots$ & $\mathrm{v}$ & $\mathrm{v}$ & $\mathrm{v}$ & $\mathrm{v}$ & $\mathrm{v}$ & $30.4 / 18.2$ & 7.6 \\
\hline 2 June & Embryo growth & 2 & $\mathrm{v}$ & $\mathrm{v}$ & $\mathrm{v}$ & $\mathrm{v}$ & $\ldots$ & $\ldots$ & $\mathrm{v}$ & $\mathrm{v}$ & $\mathrm{v}$ & $\mathrm{v}$ & $\mathrm{v}$ & $\ldots$ & $\ldots$ \\
\hline 5 June & Embryo growth & 3 & $\ldots$ & $\ldots$ & $\ldots$ & $\mathrm{v}$ & $\ldots$ & $\ldots$ & $\mathrm{v}$ & $\mathrm{v}$ & $\mathrm{v}$ & $\mathrm{v}$ & $\mathrm{V}$ & $\ldots$ & $\ldots$ \\
\hline 24 June & Late embryo growth & 1 & $\ldots$ & $\ldots$ & $\mathrm{v}$ & $\ldots$ & $\ldots$ & $\ldots$ & $\ldots$ & $\ldots$ & $\ldots$ & $\ldots$ & $\mathrm{v}$ & $32.1 / 23.2$ & 9.8 \\
\hline 25 June & Late embryo growth & 2 & $\mathrm{v}$ & $\mathrm{v}$ & $\mathrm{v}$ & $\mathrm{v}$ & $\ldots$ & $\ldots$ & $\mathrm{v}$ & $\mathrm{v}$ & $\mathrm{v}$ & $\mathrm{v}$ & $\mathrm{v}$ & $\ldots$ & $\ldots$ \\
\hline 26 June & Late embryo growth & 3 & $\ldots$ & $\ldots$ & $\mathrm{v}$ & $\ldots$ & $\ldots$ & $\ldots$ & $\mathrm{V}$ & $\mathrm{v}$ & $\mathrm{v}$ & $\mathrm{v}$ & $\mathrm{V}$ & $\ldots$ & $\ldots$ \\
\hline 19 July & Before first harvest & 1 & $\mathrm{v}$ & $\mathrm{v}$ & $\mathrm{v}$ & $\mathrm{V}$ & $\ldots$ & $\ldots$ & $\mathrm{V}$ & $\mathrm{v}$ & $\mathrm{v}$ & $\mathrm{v}$ & $\mathrm{v}$ & $33.5 / 24.4$ & 11.3 \\
\hline
\end{tabular}

a Branches of prune trees were inoculated with Monilinia fructicola at different bloom and fruit developmental stages with various inoculum concentrations.

b Artificial dew was generated to obtain different wetness durations on inoculated branches and promote latent infection.

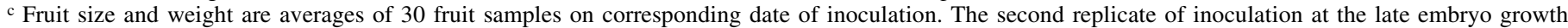
stage in Yolo County was not performed because of field flood irrigation. Only $16 \mathrm{~h}$ of wetness duration was used in the second replicate of inoculation at pit hardening stage in Butte County because of rain. Some inoculations in Tehama County were not complete due to adverse weather or field conditions.

${ }^{\mathrm{d}} \mathrm{v}$ stands for a completion of treatment. 
lation experiment in each location. Two replicated branches were used as two replicates for each combination of inoculum concentration and wetness duration.

Inoculations continued at four different fruit developmental stages on noninoculated trees in the same orchards (Table 1). The first fruit inoculation was from 3 to 8 May at the pit hardening stage. The following three inoculations were conducted from 30 May to 5 June, 23 to 28 June, and 19 to 24 July, respectively, and the corresponding stages were embryo growth, late embryo growth, and before first harvest (27) (Table 1). In each inoculation, five inoculum concentrations, 1,000, 5,000, 10,000, 20,000, and 30,000 conidia per $\mathrm{ml}$, were used. Sixty milliliters of each spore suspension was sprayed on each branch as described previously. Similar to the bloom inoculations, plastic bags $(38.1 \times$ $25.4 \times 81.3 \mathrm{~cm}$ ) were used to cover the inoculated branches. Inoculation was completed at approximately $1800 \mathrm{~h}$, and the plastic bags were uncovered at approximately 2200, 0200, 0600, and $1000 \mathrm{~h}$ to create $4,8,12$, and $16 \mathrm{~h}$ of wetness duration, respectively. Five inoculum concentrations were separated on five trees, and each tree was used for the four wetness durations. Three replicated branches were used for each combination of inoculum concentration and wetness duration. Five branches of a noninocu-
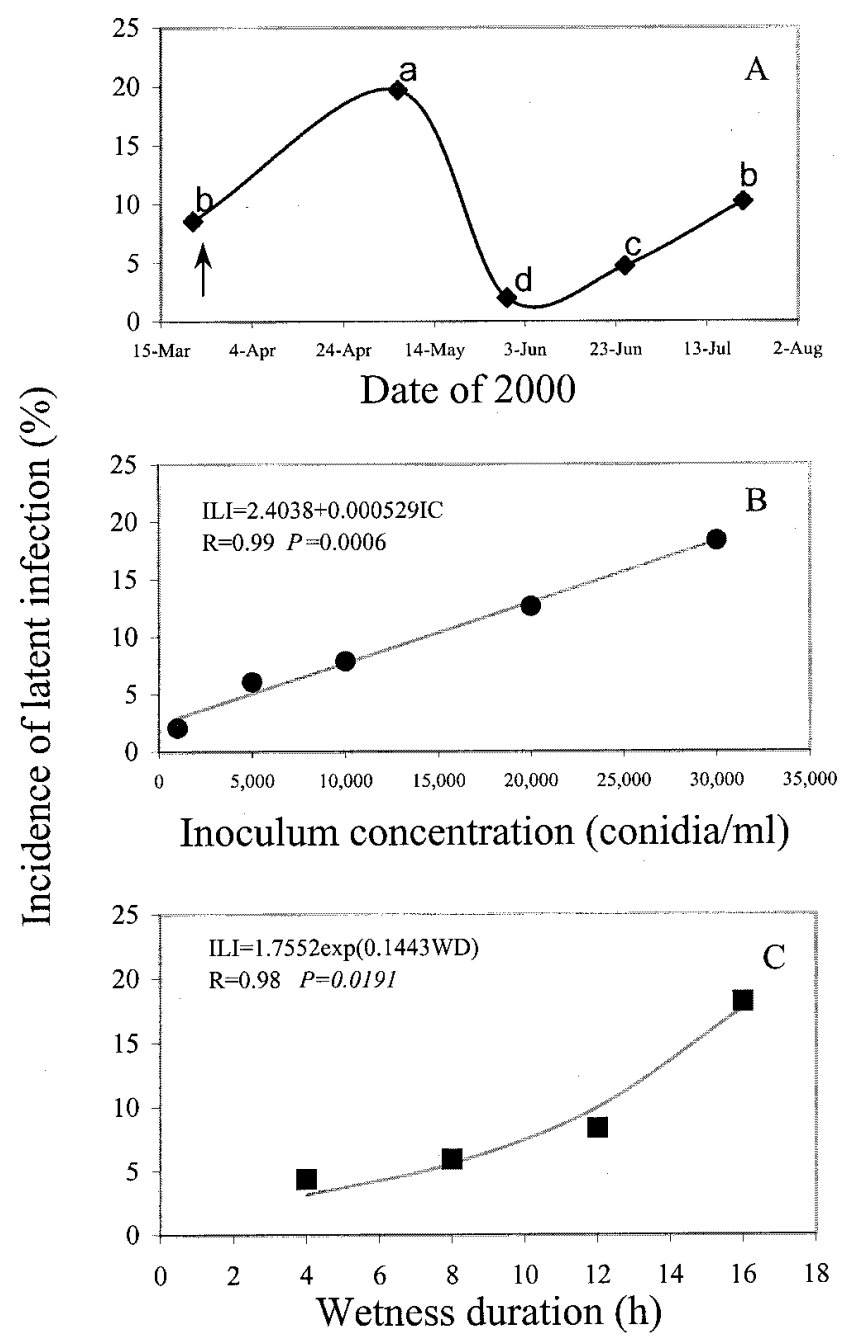

Fig. 1. A, Seasonal pattern of bloom and fruit susceptibility to latent infection by Monilinia fructicola (the arrow indicates the incidence at the full bloom stage); B, a regression between incidence of latent infection (ILI) and inoculum concentration (IC); and $\mathbf{C}$, a regression between ILI and wetness duration (WD). Data are from experiments conducted in three orchards in California. Inoculations were performed on branches of trees using different inoculum concentrations and wetness duration at different bloom and fruit developmental stages. A, Incidences with a letter in common are not significantly different at $P<0.05$. lated tree were sprayed with $50 \mathrm{ml}$ of water, kept wet for $16 \mathrm{~h}$, and served as the noninoculation control for each inoculation experiment in each location. Each inoculation experiment was repeated twice at each growth stage for most cases (Table 1). However, inoculation at the late embryo growth stage in the orchard of Yolo County (Davis) was conducted only once (Table 1) because of difficulties in entering the field due to flood irrigation. In the second replication of inoculation, at the pit hardening stage in the orchard of Butte County (Gridley), only the 16-h wetness duration was created because of rain (Table 1). Inoculation was repeated three times at the embryo growth and late embryo growth stages in the orchard of Tehama County (Los Molinos), using different inoculum concentrations or wetness durations (Table 1) because of field and weather situations. In each inoculation, natural dew was physically detected one-half hour after uncovering bags. The data affected by natural dew and rains were omitted from the data analysis. A data logger (Onset Company, Pocasset, MA) was used in each orchard to record hourly temperature during the experiments.

A split-split-plot design (9) was applied in this study. Location was treated as replication of the experiments. Developmental stage was treated as main-plot factor. Inoculum concentration was treated as subplot factor because separate trees were used, and wetness duration was sub-subplot factor.

Fruit on all inoculated trees were maintained until harvest. Depending on the location of the orchard, harvest dates ranged from 31 July to 4 August (approximately 3 weeks before commercial harvest). Fruit showing sporulation or appearing as mummies were recorded during harvest. Fruit of each replicate of treatment were placed in a paper bag and stored at $4^{\circ} \mathrm{C}$ until processed for detection of latent infection.

Detection of latent infection. The overnight freezing incubation technique $(20,21)$ was used to determine the incidence of fruit with latent infection. Briefly, plastic containers $(40 \times 24 \times 12 \mathrm{~cm})$ and screens were sterilized by soaking in $10 \%$ commercial bleach for at least $8 \mathrm{~h}$. For each sample, fruit were surface sterilized in a chlorine solution ( $32 \mathrm{ml}$ of $0.525 \%$ sodium hypochlorite, $32 \mathrm{ml}$ of $95 \% \mathrm{ETOH}$, and $0.01 \mathrm{ml}$ of surfactant Tween 20 in 2 liters of water) for approximately 15 to $20 \mathrm{~min}$. The fruit were washed with sterile distilled water 10 times and placed on a sterilized plastic screen in a container with $150 \mathrm{ml}$ of water at the bottom. The containers were placed in a freezer at $-16^{\circ} \mathrm{C}$ for $10 \mathrm{~h}$ initially and on a laboratory bench at $23 \pm 2{ }^{\circ} \mathrm{C}$ for 5 days. By this time, fruit covered with sporulation of M. fructicola was recorded, and incidence as percentage of brown rot of fruit was calculated for each sample.

Data analysis. Data of incidence of fruit with latent infection for each sample were transformed with the arcsine transformation

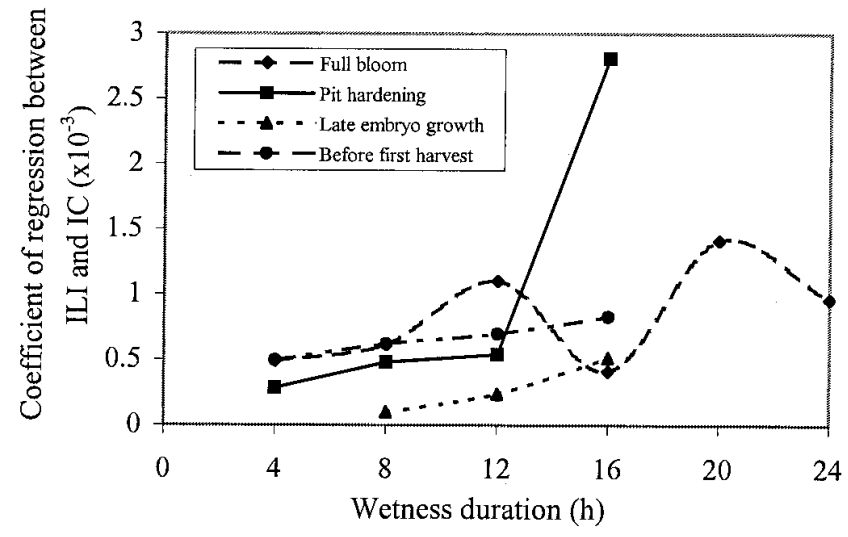

Fig. 2. Relationships between regression coefficient and wetness duration. The regressions between incidence of latent infection (ILI) of prune fruit caused by Monilinia fructicola and inoculum concentration (IC) were obtained at different bloom and fruit developmental stages. 
for overall analysis (9). Variances from location, developmental stage, inoculum concentration, wetness duration, and all interactions were analyzed using the PROC general linear models (GLM) of SAS (version 8.0, SAS Institute, Cary, NC). In this analysis, data of the complete treatments (five inoculum concentrations and four wetness durations at $4,8,12$, and $16 \mathrm{~h}$ ) were used. The data of incomplete treatments were added in the following regression analyses. Data of locations were combined because analysis of variance showed no significant difference among locations and with homogeneous variances. Further analysis was conducted with GLM in which the developmental stage was treated as replication, inoculum concentration was treated as the main-plot factor, and wetness duration was the subplot factor.

Comparisons in mean ILI among developmental stages were conducted using LSD based on the corresponding error term. The means of ILI from all treatments of inoculum concentration and wetness duration for each inoculation date were used to determine the seasonal pattern of susceptibility to latent infection. Regressions between overall mean ILI and inoculum concentration and between overall mean ILI and wetness duration were conducted using the software SigmaPlot (version 5.0, SPSS Inc., Richmond, CA). Data of ILI versus inoculum concentration for each combination of stage and wetness duration, and data of ILI versus wetness duration for each combination of stage and inoculum concentration were plotted to determine the existence of either linear or nonlinear relationships. Linear $(Y=\alpha+\beta X)$ and exponential $(Y=$ $a \times e^{b X}$ or $\left.Y=Y_{0}+a \times e^{b X}\right)$ curves were tested for each relationship. The residual of $Y$ versus $X$ was used to obtain residual plot for linear and exponential regressions, and the regression with the highest $R$ value and with a residual plot showing more random scatter pattern (5) was selected. Analysis of homogeneity of regression coefficients (9) was conducted to determine the significant difference in regression coefficient between any two regressions.

Hourly temperatures for each wetness duration were obtained by a data logger. However, in contrast to experiments with consistent temperatures, temperatures in the field changed during the wetness durations. Using an average temperature for a wetness duration, especially for those longer than $4 \mathrm{~h}$, may not be valid because changing temperatures have different effects on infection. Therefore, in this study we used an adjusted average temperature for each wetness duration.

The following Gaussian equation was obtained from previous experiments (19) that studied the effects of temperature on blossom blight of prune under favorable conditions, $10^{4}$ conidia per $\mathrm{ml}$ of inoculum concentration, and 24-h wetness duration:

$$
\mathrm{PBB}=0.95 \times \exp \left\{-0.5[(T-21.75) / 5.90]^{2}\right\}
$$

where PBB is the proportion of blighted blossoms (0 to 1$)$ and was used below as the proportion of latent infection affected by temperature, and $T$ is temperature in degree Celsius. This equation describes a quantitative relationship between temperature and disease incidence with an exponential one-peak curve. The peak of the curve is at 0.95 of $\mathrm{PBB}$ when temperature is $21.75^{\circ} \mathrm{C}$. This equation can be used to estimate the quantitative effect ( 0 to 1 ) of temperature on disease incidence. The assumption for using this equation is that the optimum temperature is $21.75^{\circ} \mathrm{C}$ and disease incidence could be exponentially decreased under temperatures below or above the optimum temperature. The equation is valid for a temperature ranging from 5 to $40^{\circ} \mathrm{C}$. To calculate adjusted temperature, the following function was used for each wetness duration:

$$
T_{a}=T_{m} \sum_{i=1}^{n}\left(\mathrm{PBB}_{i} / \mathrm{PBB}_{m}\right)
$$

where $T_{a}$ is the adjusted temperature for a given wetness duration, $T_{m}$ is mean temperature of this duration (average of hourly temperature), $\mathrm{PBB}_{i}$ is $\mathrm{PBB}$ for temperature $T$ at hour $i$ of the wetness duration calculated from equation $1, \mathrm{PBB}_{m}$ is $\mathrm{PBB}$ calculated by assigning $T_{m}$ as $T$ in equation 1 , and $n$ is the number of hours of the wetness duration. A computer program MEANTEMP was developed using the Turbo C++ compiler (Borland Software Corporation, Scotts Valley, CA) to calculate the adjusted temperature for each wetness duration. Mean ILI at each adjusted temperature was calculated for each combination of developmental stage, inoculum concentration, and wetness duration condition.
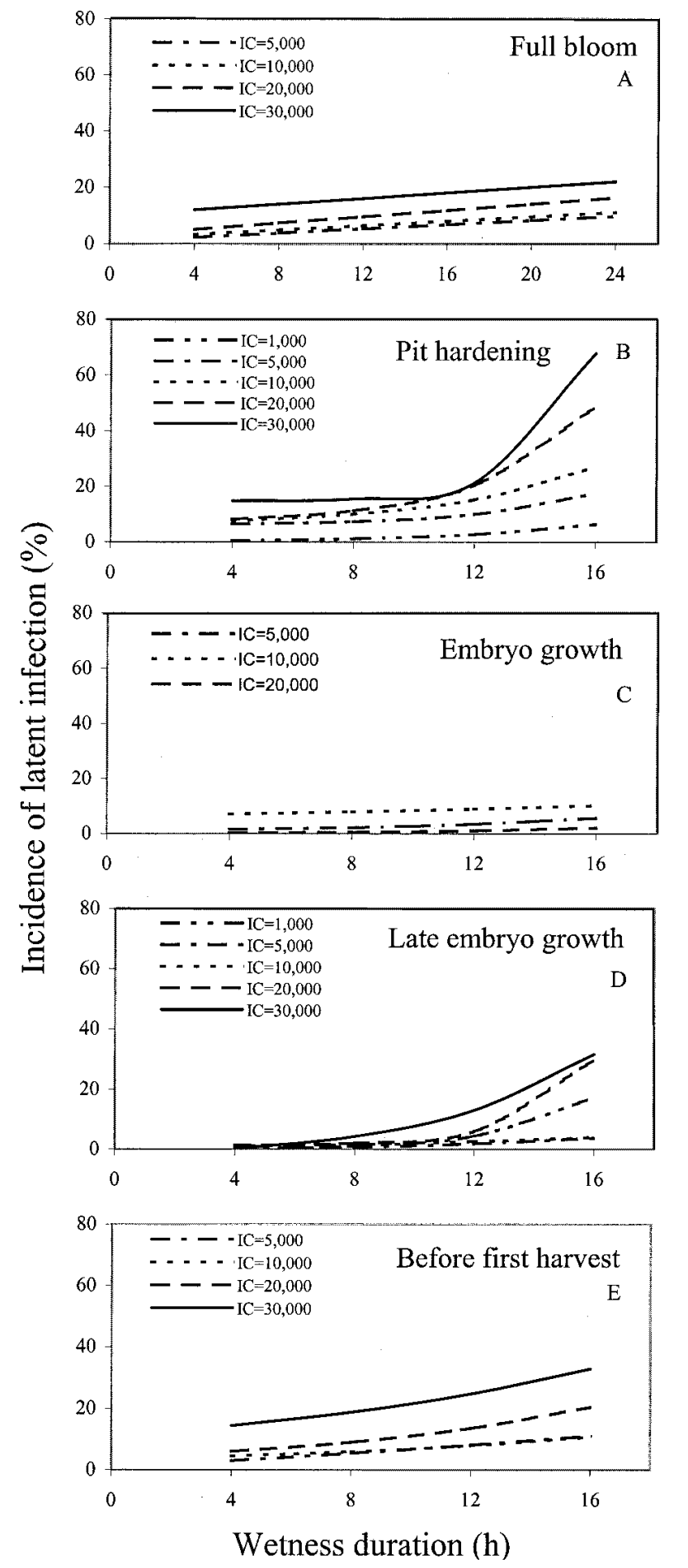

Fig. 3. Relationships between incidence of latent infection of prune by Monilinia fructicola and wetness duration for different bloom and fruit developmental stages. Each curve was obtained from a linear or exponential regression. $\mathrm{IC}=$ inoculum concentration. 


\section{RESULTS}

Overall, analysis demonstrated that the variance from location was not significant $(P=0.6902)$, and other factors and their interactions were significant at $P<0.0001$. Data of three locations were combined and further GLM showed that developmental stage, inoculum concentration, wetness duration, and their interactions were all significant at $P<0.0001$.

Overall comparison in ILI among developmental stages demonstrated that stages were significantly different from each other at $P<0.001$, except for those between the bloom and the before first harvest stage (Fig. 1A). The average ILI caused at bloom stage was approximately $8.6 \%$. However, the fruit susceptibility to infection increased after full bloom, and this increase lasted approximately 1 month. Considering the entire prune growing season, the most susceptible stage to infection was before pit
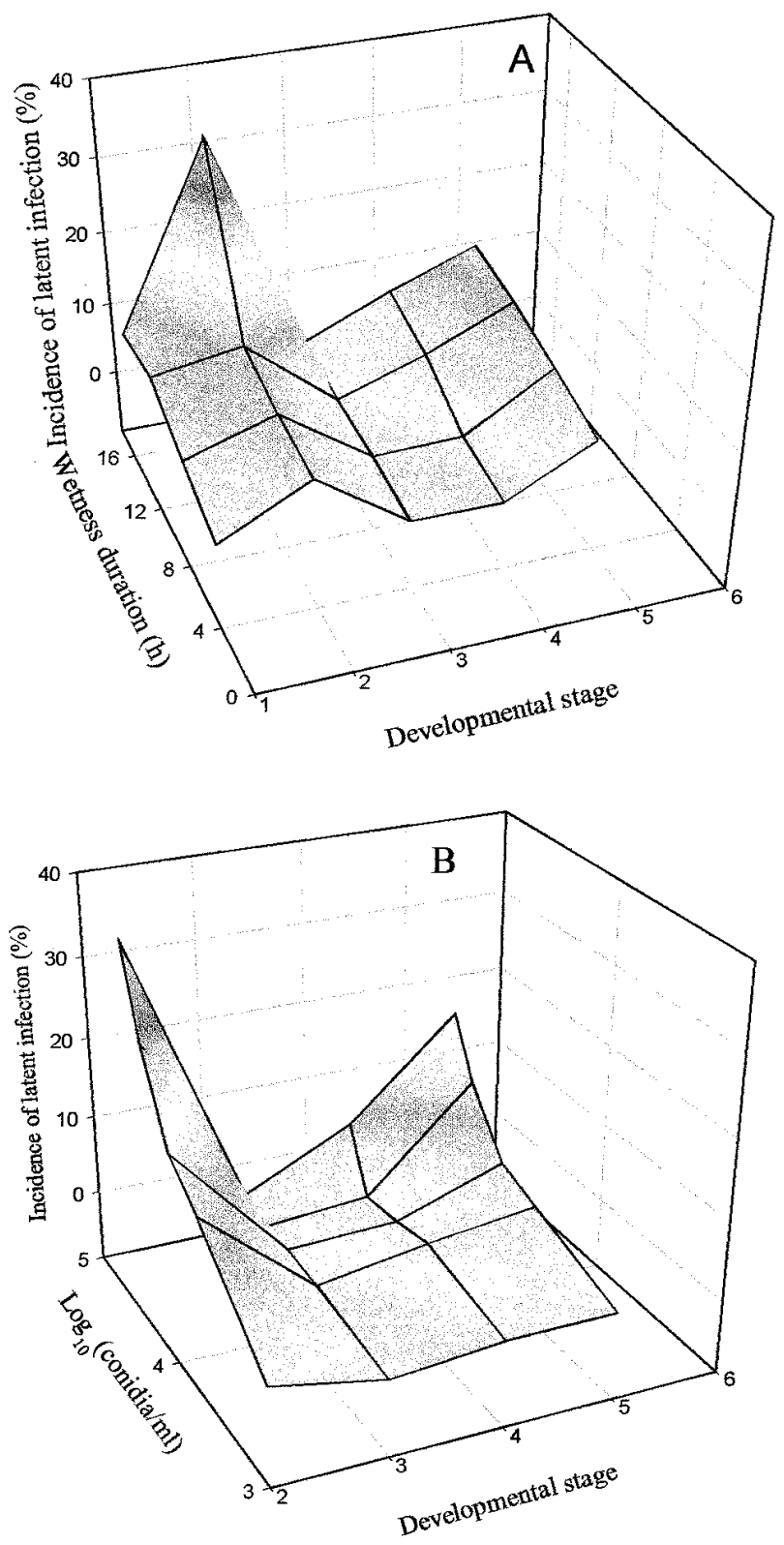

Fig. 4. A, Relationships among incidence of latent infection (ILI) by Monilinia fructicola, bloom and fruit developmental stage, and wetness duration; and $\mathbf{B}$, among ILI, developmental stage, and inoculum concentration. Data are from inoculations at $\mathbf{A}$, five or $\mathbf{B}$, four developmental stages: $1=$ full bloom, 2 = pit hardening, 3 = embryo growth, 4 = late embryo growth, and $5=$ before first harvest. hardening (from late April to early May). After early May, the susceptibility to infection dramatically decreased until it reached the lowest level in early June (Fig. 1A). Along with increasing fruit size (Table 1) and maturity, the susceptibility of fruit to infection increased from early June, reaching a moderate level in late July, approximately 3 to 4 weeks before commercial harvest
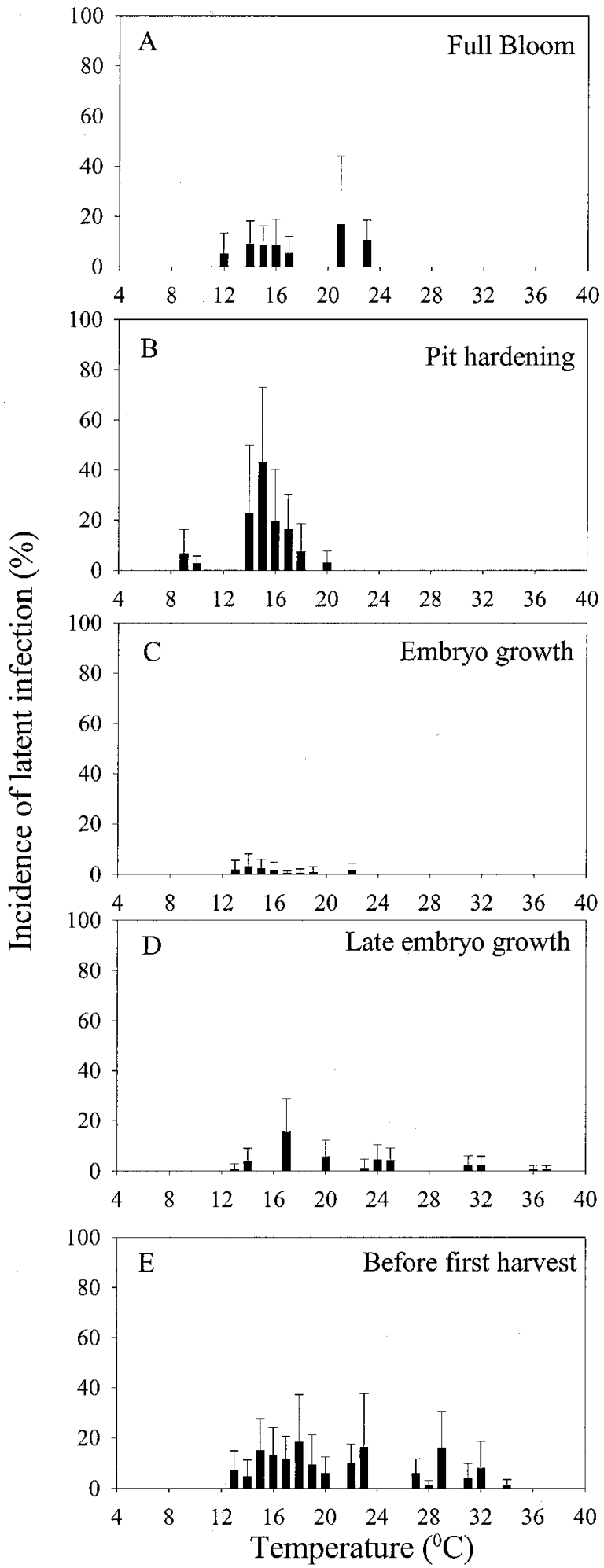

Fig. 5. Mean incidence of latent infection (ILI) of prune fruit by Monilinia fructicola at different temperatures at bloom and fruit developmental stages. At each stage, five inoculum concentrations of $M$. fructicola and six (for full bloom stage) or four (for four fruit stages) wetness durations were used in each inoculation. Each bar represents an average ILI from the treatments that encountered the corresponding temperature. 
(Fig. 1A). In general, fruit were more susceptible to infection when they were young and mature than when they were in middle age (late May to early June).

An overall linear relationship between ILI and inoculum concentration was obtained (Fig. 1B). In general, an increase of 1,000 conidia per $\mathrm{ml}$ brought approximately $0.5 \%$ increase of ILI. Moreover, an increase of wetness duration led to an exponential increase of ILI (Fig. 1C), and the rate of exponential increase is 0.1443 ILI per hour of wetness duration.

Linear equations significantly described the relationship between ILI and inoculum concentration for most combinations of developmental stage and wetness duration. At the full bloom stage, increase of inoculum concentration significantly $(P<0.05)$ and positively related to the increase of ILI for all six wetness durations (data not shown). The increase rates (regression coefficients) were lower for 4 and $16 \mathrm{~h}$ of wetness durations than for the other two wetness durations (Fig. 2). When fruit development reached the pit hardening stage, inoculum concentration continuously affected ILI for all four wetness durations $(P<0.05)$, and the regression coefficient increased with increased wetness duration (Fig. 2). Generally, increase of wetness duration enhanced the unit effect of inoculum concentration, especially when wetness duration was longer than $12 \mathrm{~h}$ (Fig. 2). However, correlation between ILI and inoculum concentration was not found at the embryo growth stage when wetness duration was longer than $4 \mathrm{~h}$, implying that a change in inoculum concentration at this stage did not relate to a change of ILI when 8,12 , and $16 \mathrm{~h}$ of wetness duration occurred. Trends similar to those at the pit hardening stage were observed at late embryo growth and before first harvest stages (Fig. 2). Therefore, ILI increased linearly with increased inoculum concentration, and these relationships were affected by wetness duration at the most developmental stages.

The effects of wetness duration on ILI were also quantitatively determined. At the bloom stage, significant linear relationships between ILI and wetness duration were obtained for inoculum concentrations of 1,000 to 30,000 conidia per ml (Fig. 3A). An increase of wetness duration by $1 \mathrm{~h}$ led to an increase of ILI by 0.37 to $0.56 \%$. Although the regression coefficients were different among some inoculum concentrations, increase of inoculum concentration did not clearly relate to increase of regression coefficient (data not shown). At the pit hardening stage, the exponential regression coefficients ranged from 0.20 to 0.52 . The regression coefficient for inoculum concentration of 30,000 conidia per $\mathrm{ml}$ was significantly higher than regression coefficients for inoculum concentrations of 1,000 and 10,000 conidia per ml (Fig. 3B). At embryo growth stage, although the ILI and wetness duration were not correlated for inoculum concentrations of 1,000 and 30,000 conidia per ml (Fig. 3C), similar exponential relationships were still found for other inoculum concentrations. The exponential regression coefficients ranged from 0.11 to 0.45 for late embryo growth stage (Fig. 3D) and from 0.02 to 0.10 for before first harvest stage (Fig. 3E). In a summary of the above results by three-dimensional graphs (Fig. 4), both inoculum concentration and wetness duration had greater effects on latent infection at the early and late stages than at the middle stages (Fig. 4).

Similar to the effects on blossom blight (18), temperature affected ILI on fruit. At the pit hardening stage, adjusted temperature ranged from 9 to $21^{\circ} \mathrm{C}$, and the estimated optimum temperature was $15.2^{\circ} \mathrm{C}$ (Fig. 5B). At embryo growth stage, the adjusted temperature range changed to 13 to $23^{\circ} \mathrm{C}$, and the estimated
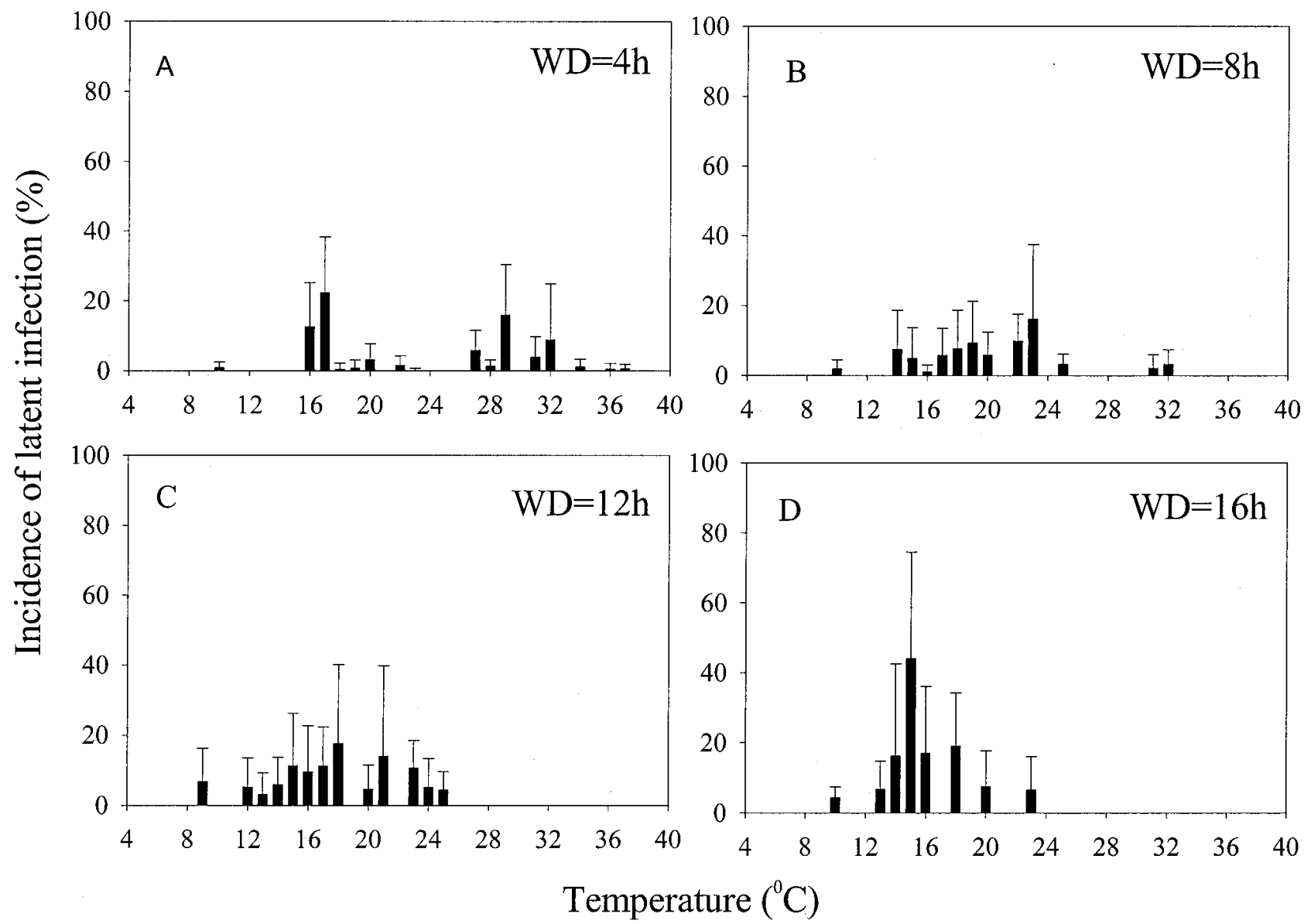

Fig. 6. Mean incidence of latent infection (ILI) of prune fruit by Monilinia fructicola at different temperatures for four wetness durations (WD). Each bar represents an average ILI from different bloom and fruit developmental stages and the different inoculum concentrations that encountered the corresponding temperature. 
optimum temperature was approximately $14.0^{\circ} \mathrm{C}$ (Fig. 5C). However, very low levels of latent infection were detected at this stage. At late embryo growth stage, distribution of ILI over temperature was wider than distribution of ILI over temperature at previous stages (Fig. 5A to C), and the adjusted temperatures ranged from 13 to $37^{\circ} \mathrm{C}$ (Fig. 5D). Although the highest ILI was observed at approximately $17^{\circ} \mathrm{C}$, a number of latent infections still occurred at over $30^{\circ} \mathrm{C}$. The temperature at the before first harvest stage ranged from 13 to $34^{\circ} \mathrm{C}$ (Fig. 5E). Although some latent infections were observed at temperatures higher than $23^{\circ} \mathrm{C}$, most latent infections occurred between 13 and $23^{\circ} \mathrm{C}$. There were more latent infections detected at the before first harvest stage (Fig. 5E) than those at the embryo growth and late embryo growth stages (Fig. 5C and D). However, the distribution of latent infection was much less aggregated than that at the pit hardening stage (Fig. 5B).

The distributions of ILI over temperature were discrepant at different wetness durations. At the 4-h wetness duration, there was no clear relationship between temperature and ILI (Fig. 6A). When the wetness duration increased to $8 \mathrm{~h}$, a decentralized distribution of ILI over temperature was observed, and the estimated optimum temperature was approximately $23^{\circ} \mathrm{C}$, and some latent infections were detected at 31 and $32^{\circ} \mathrm{C}$ (Fig. 6B). At the 12-h wetness duration, the detected latent infections distributed from 9 to $25^{\circ} \mathrm{C}$ and the estimated optimum temperature decreased to $18^{\circ} \mathrm{C}$ (Fig. 6C). More latent infections were detected at the 16-h wetness duration. The optimum temperature continuously decreased to $15^{\circ} \mathrm{C}$, although the distribution of ILI was more aggregated compared with the other stages (Fig. 6D).

The optimum temperature was higher at bloom stage than at the other stages (Fig. 7A). In addition to fruit development, ILI increased until early May, but the optimum temperature for latent infection decreased during this period (Fig. 7A). This implies that during the period from bloom to early pit hardening, fruit were
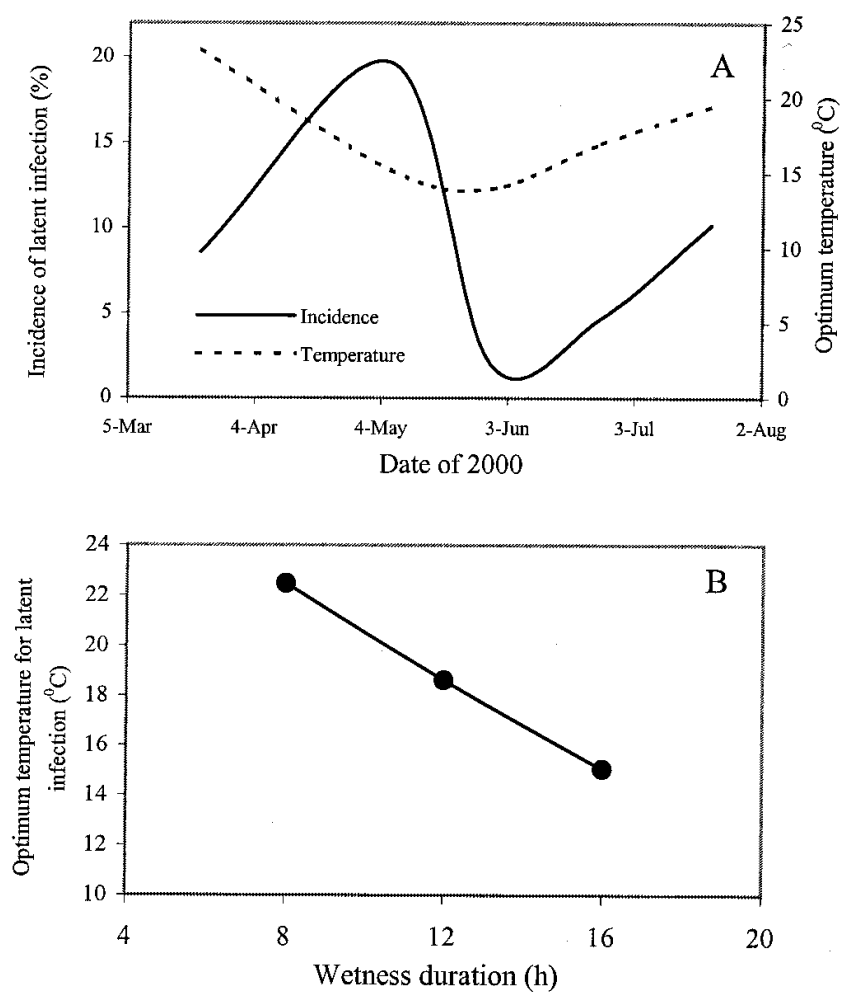

Fig. 7. A, Incidence of latent infection (ILI) of prune fruit by Monilinia fructicola and optimum temperature versus dates in prune-growing season, and $\mathbf{B}$, a relationship between optimum temperature for latent infection and wetness duration. Optimum temperatures are estimated from relationships between mean ILI and temperature for different bloom and fruit developmental stages and wetness durations. more susceptible to infection, although optimum temperatures were relatively lower than those late in the season. However, resistance to infection increased through fruit development until late May to early June, and temperature has much less effect on infection during this period. Along with increased fruit susceptibility to infection at later stages, optimum temperature for latent infection increased. The optimum temperature for latent infection linearly decreased with increased wetness durations from 8 to $16 \mathrm{~h}$ (Fig. 7B).

\section{DISCUSSION}

This study has determined a seasonal pattern of prune bloom and fruit susceptibility to latent infection by M. fructicola. The bloom and fruit susceptibility to latent infection changed over the growing season. Latent infection can initiate at bloom stage. However, susceptibility to infection increased after bloom until the pit hardening stage, lasting about 1 month. Susceptibility to infection decreased during embryo growth, and fruit became more resistant until late embryo growth stage. Fruit became susceptible again after this stage until harvest. Therefore, the order of developmental stage in susceptibility to latent infection is before pit hardening, bloom and before first harvest, late embryo growth, and embryo growth.

A similar seasonal pattern was previously observed by Biggs and Northover through inoculations of detached peach fruit (2). They reported that peach fruit were susceptible to infection for a period of 3 weeks in June, followed by a decreased susceptibility during July, and subsequently increased susceptibility to infection approximately 2 to 3 weeks before full ripeness. They concluded that the least susceptibility to latent infection was at pit hardening. Similar patterns were also detected on peach and nectarine in a separate study (14). Our study not only confirms the above conclusions on prune fruit, but also provides new information regarding an outlook of latent infection in nature at both bloom and fruit developmental stages in commercial orchards.

Latent infection of fruit was quantitatively affected by inoculum concentration and wetness duration. In general, ILI linearly increased with increased inoculum concentration, and the quantitative relationships were different at different wetness duration and developmental stages. However, the effect of inoculum concentration on ILI was not detected at the resistant stage. The unit of increase of inoculum concentration on infection became greater with increased wetness duration. In other words, increasing wetness duration may proportionally enhance the effect of inoculum concentration on latent infection. At bloom stage, wetness duration linearly affected latent infection. However at fruit developmental stages, ILI exponentially increased with increased wetness duration. Because at full bloom period, temperatures were usually lower than the optimum temperature for infection late in the season $\left(23\right.$ to $\left.25^{\circ} \mathrm{C}\right)$, ILI may linearly increase with increased temperature within a lower temperature range. Because weather becomes warmer in the growing season, higher than optimum temperature may restrict infections, and quantitative effects of wetness duration on infection could be changed (Fig. 5).

Biggs and Northover (3) found that on harvested peach fruit, optimum temperatures for infection ranged from 22.5 to $25^{\circ} \mathrm{C}$ and more than $70 \%$ of the fruit were infected after 12 -h wetness duration at temperatures below $27.5^{\circ} \mathrm{C}$. In another study under controlled conditions (2), they reported that at the lower inoculum concentrations $\left(10^{3}\right.$ to $10^{4}$ conidia per $\left.\mathrm{ml}\right)$, fruit became resistant earlier in the season and were susceptible later in the season compared with those inoculated at the highest inoculum concentration $\left(10^{6}\right.$ conidia per $\left.\mathrm{ml}\right)$. Corbin (6) reported that on harvested peach, plum, and cherry fruits, higher inoculum dosage led to a shorter incubation period, and green fruit could be infected by high inoculum dosages of $M$. fructicola when they were noninjured and by low inoculum dosages when they were injured. 
Additionally, this study found that higher inoculum concentration with longer wetness duration had an enhanced effect on latent infection at a susceptible fruit stage compared with a resistant stage (Fig. 4). These results are important when considering disease prediction.

The estimated optimum temperature relating to maximum ILI was different at different developmental stages. Our temperature data showed that the average temperatures in orchards were higher at late embryo growth stage than at embryo growth stage, but the average ILI was higher at late embryo growth stage than at embryo growth stage (Figs. 1A and 5C and D). Thus, when fruit reach maturity, fruit susceptibility increases although temperature may increase. A similar situation, observed by Biggs and Northover (3), concluded that weather conditions did not differ greatly during the period in which susceptibility of fruit to infection changed. These findings imply that even high temperature could not restrict the increase of fruit susceptibility to latent infection late in the season.

Interactions between temperature and wetness duration were also observed. When wetness duration is too short, temperature may not be a critical factor for latent infection (Fig. 6). However, the estimated optimum temperature decreased with increased wetness duration of longer than $8 \mathrm{~h}$ (Fig. 7B). Temperature is an important predictive factor throughout the growing season, but it is affected by other factors. For example, our previous study (18) found that wetness duration was a more important factor than temperature for latent infection when low inoculum concentrations were used. However, when inoculum concentration was increased, wetness duration was less important than temperature.

A practical process of risk assessment for latent infection of fruit is to take into account the seasonal pattern of fruit susceptibility to infection using different predictive factors. Latent infection could happen at bloom stage, and inoculum potential, wetness duration, and temperature are critical factors in disease prediction. These factors are more critical on young fruit than on fruit in middle age. The risk of infection could decrease after the pit hardening stage until the embryo growth stage. However, it is important to consider the increase of fruit susceptibility to infection after embryo growth. In summary of this study, wetness duration could always be a factor in disease prediction. If shorter than 4-h wetness duration occurs, effect of temperature on infection could be ignored. If longer than 4 -h wetness duration occurs at the resistant stage, the risk of latent infection might be fairly low. Thus, if rains occur during this period, they will not be critical to disease development, and growers need not act for disease control. Inoculum potential in orchards is the other predictive factor, especially early and late in the season. However, it can be ignored at the resistant stage, unless extremely favorable conditions such as lower temperature with rain for longer than 1 day occur. At the stage in which fruit may become more resistant to infection, inoculum potential from thinned fruit bearing sporulation may be diminished to a minimal level because of orchard conditions and cultural practices. However, in orchards with higher inoculum potential and a disease history, consideration of wetness duration and temperature in disease prediction at this stage is still needed. Because fruit become more susceptible to latent infection as fruit maturity increases, even a relatively higher temperature can bring about a certain level of infection at later stages than at earlier stages. The optimal temperature range for latent infection may become wider at later fruit developmental stages. Because early infected fruit with sporulation can serve as inoculum sources, latent infection occurring at the early stages should be predicted by estimating inoculum potential.

Because inoculum potential is important for estimating latent infection, spore density produced from thinned fruit on the orchard floor could be a factor contributing to latent infection. Fruit thinning of prune orchards in California usually starts in late April or early May, and its timing is determined by other production factors. Fruit thinning usually occurs at the stage most susceptible to latent infection. Therefore, influence of environments on sporulation of $M$. fructicola on thinned fruit becomes important for prediction of latent infection. Our previous study (18) determined the quantitative relationships between water content of thinned prune fruit and sporulation. The information is helpful in predicting inoculum potential in fields.

Different from peach, plum, and other stone fruits that require storage after harvest and during which latent infection may cause fruit rot, the majority of commercial prune fruit is destined for dehydration immediately after harvest. Therefore, main yield losses are from symptomatic fruit with sporulation or those that become mummies on trees by harvest. The critical period of infection and favorable conditions leading to the appearance of fruit rot symptoms before harvest are still unknown. We observed that a few branches inoculated at bloom to late embryo stages had mummies by harvest, but none of those inoculated at the before first harvest stage. Disease prediction for the period after late embryo growth stage and information on the conditions under which latently infected fruit could become mummies are needed. Although this study was conducted on prune fruit, some important conclusions may be applied on other stone fruits such as peach, plum, and nectarine. However, prunes are good materials for studying latent infection of fruit by $M$. fructicola, because determination of latent infection by destructive fruit samplings over the whole growing season is much less costly than using other fruits.

In summary, the results of this study imply that latent infection should not be ignored in a disease management program. Chemical control only at bloom stage for blossom blight might not be sufficient for orchards with a history of disease or a high disease pressure. Our survey (Y. Luo and T. J. Michailides, unpublished data) in orchards with high inoculum potential demonstrated that severe fruit rot (over 20\%) could occur in orchards where chemical control was applied only at bloom. However, a control strategy should be developed based on estimations of possible risk of latent infection that is influenced by the predictive factors studied above. Quantitative relationships between ILI and these factors will be used in development of a disease prediction and risk assessment system to guide prune growers in their efforts of brown rot control, especially in orchards with a relatively low inoculum potential.

\section{ACKNOWLEDGMENTS}

This study was supported by the California Prune Broad. We thank W. H. Olson (Cooperative Extension, Butte County) and B. Kirkpatrick (Department of Plant Pathology, University of California, Davis) for their help to identify prune orchards; W. H. Krueger (Cooperative Extension, Glenn County) for his help in disease surveys; R. P. Buchner (Cooperative Extension, Tehama County), M. Gilles, and C. Gilles for locating a prune orchard in Tehama County for part of these experiments; and B. Koga, M. Katendi Beta, and Z. Ma for assistance in fruit processing for latent infection.

\section{LITERATURE CITED}

1. Biggs, A. R., and Northover, J. 1985. Inoculum sources for Monilinia fructicola in Ontario peach orchards. Can. J. Plant Pathol. 7:302-307.

2. Biggs, A. R., and Northover, J. 1988. Early and late-season susceptibility of peach fruits to Monilinia fructicola. Plant Dis. 72:1070-1074.

3. Biggs, A. R., and Northover, J. 1988. Influence of temperature and wetness duration on infection of peach and sweet cherry fruits by Monilinia fructicola. Phytopathology 78:1352-1356.

4. Byrde, R. J. W., and Willetts, H. J. 1977. The Brown Rot Fungi of Fruit: Their Biology and Control. Pergamon Press, Oxford.

5. Campbell, C. L., and Madden, V. L. 1990. Introduction to Plant Disease Epidemiology. John Wiley \& Sons, New York.

6. Corbin, J. B. 1963. Factors determining the length of the incubation period of Monilinia fructicola (Wint.) Honey in fruits of Prunus spp. Aust. J. Agric. Res. 14:51-60.

7. Cruickshank, R. H., and Wade, G. C. 1992. The activation of latent 
infections of Monilinia fructicola on apricots by volatiles from the ripening fruit. J. Phytopathol. 136:107-112.

8. Emery, K. M., Michailides, T. J., and Scherm, H. 2000. Incidence of latent infection of immature peach fruit by Monilinia fructicola and relationship to brown rot in Georgia. Plant Dis. 84:853-857.

9. Gomez, K. A., and Gomez, A. A. 1984. Statistical Procedures for Agricultural Research. 2nd ed. John Wiley \& Sons, New York.

10. Holtz, B. A., Michailides, T. J., and Kölliker, R. 1995. Thinned infected stone fruit as inoculum sources of Monilinia fructicola in California. (Abstr.) Phytopathology 85(suppl.):S1194.

11. Hong, C. X., Holtz, B. A., Morgan, D. P., and Michailides, T. J. 1997. Significance of thinned fruit as a source of the secondary inoculum of Monilinia fructicola in California nectarine orchards. Plant Dis. 81:519524.

12. Hong, C. X., and Michailides, T. J. 1999. Mycelial growth, sporulation, and survival of Monilinia fructicola in relation to osmotic potential and temperature. Mycologia 91:871-876.

13. Hong, C. X., Michailides, T. J., and Holtz, B. A. 1998. Effects of wounding, inoculum density, and biological control agents on postharvest brown rot of stone fruits. Plant Dis. 82:1210-1216.

14. Ibbotson-Darhower, H., Hickey, K. D., and Tavis, J. W. 1998. Susceptibility of peach and nectarine fruit at different developmental stages to Monilinia fructicola. (Abstr.) Phytopathology 88(suppl.):S130.

15. Jerome, S. M. R. 1958. Brown rot of stone fruits: Latent contamination in relation to spread of the disease. J. Aust. Inst. Agric. Sci. 24:132-140.

16. Kable, P. F. 1965. Air dispersal of spores of Monilinia fructicola in peach orchards. Aust. J. Exp. Agric. Anim. Husb. 5:166-171.

17. Landgraf, F. A., and Zehr, E. 1982. Inoculum sources for Monilinia fructicola in South Carolina peach orchards. Phytopathology 72:185-190.

18. Luo, Y., Ma, Z., and Michailides, T. J. 2001. Analysis of factors affecting latent infection and sporulation of Monilinia fructicola on prune fruit. Plant Dis. 85:999-1003.

19. Luo, Y., Morgan, D. P., and Michailides, T. J. 2001. Risk analysis of brown rot blossom blight of prune caused by Monilinia fructicola. Phytopathology 91:759-768.

20. Michailides, T. J., Morgan, D. P., and Felts, D. 2000. Detection and significance of symptomless latent infection of Monilinia fructicola in California stone fruit. (Abstr.) Phytopathology 90(suppl.):S48.

21. Michailides, T. J., Morgan, D. P., Felts, D., and Krueger, W. 1996. Ecology and epidemiology of prune brown rot and new control strategies. Pages 109-123 in: 1996 Prune Research Report and Index of Prune Research. California Prune Board, Pleasanton.

22. Michailides, T. J., Morgan, D. P., Holtz, P. A., Guo, L., and Hong, C. 1995. Cultural and chemical controls of preharvest and postharvest brown rot of peach, nectarines, and plums, and Mucor rot of late varieties of nectarines and plums. Pages 86-101 in: Res. Rep. Calif. Tree Fruit Agreement, Reedley, CA.

23. Michailides, T. J., Morgan, D. P., Holtz, P. A., and Hong, C. 1995. Biology, ecology, and epidemiology of Monilinia species, and management of prune brown rot with late-spring and early-summer fungicide sprays. Pages 79-100 in: Prune Research Report and Index of Prune Research. California Prune Board, Pleasanton.

24. Northover, J., and Biggs, A. R. 1995. Effect of conidial concentration of Monilinia fructicola on brown rot development in detached cherries. Can. J. Plant Pathol. 17:205-214.

25. Northover, J., and Cerkauskas, R. F. 1994. Detection and significance of symptomless latent infections of Monilinia fructicola in plums. Can. J. Plant Pathol. 16:30-36.

26. Phillips, D. J. 1984. Effect of temperature on Monilinia fructicola spores produced on fresh stone fruits. Plant Dis. 68:610-612.

27. Polito, V. S. 1981. Flower and fruit development. Pages 46-52 in: Prune Orchard Management. D. E. Ramos, ed. Univ. Calif. Div. Agric. Sci. Publ. 3269.

28. Sholberg, P. L., Ogawa, J. M., and Manji, B. T. 1981. Diseases of prune blossoms, fruits, and leaves. Pages 121-125. in: Prune Orchard Management. Univ. Calif. Div. Agric. Sci. Publ. 3269.

29. Wade, G. C. 1956. Investigations on brown rot of apricots caused by Sclerotinia fructicola (Wint.) Rehm. I. The occurrence of latent infection in fruit. Aust. J. Agric. Res. 7:504-516.

30. Wade, G. C., and Cruickshank, R. H. 1992. The establishment and structure of latent infections with Monilinia fructicola on apricot. J. Phytopathol. 136:95-106. 